\title{
Examining the Role of Organization Policy as Impediments to Knowledge Sharing in ERP Post Implementation
}

\author{
${ }^{1}$ Adegbenro, D.R., ${ }^{2}$ Longe, O.B. \& ${ }^{3}$ Okolo, O., \\ 182Information Systems Department \\ 3Information Literacy Unit \\ American University of Nigeria \\ Yola, Adamawa State, Nigeria \\ E-mails: dimeji.adegbenro@aun.edu.ng olumide.longe@aun.edu.ng, omachi.okolo@aun.edu.ng;;
}

\begin{abstract}
Knowledge is now being seen as the most important strategic resource in organizations, and the management of this knowledge either tacit or explicit knowledge is considered critical to organizational success. explicit knowledge can be accessed quickly, in contrast, the process of accessing tacit knowledge which dwells in the intellectual base of an employee is of varying dynamics. In this study, organization policy role in knowledge sharing Post ERP Implementation was critically investigated. If organizations have to capitalize on the knowledge they possess, they have to understand how knowledge is created, shared, and used within the organization. Knowledge exists and is shared at different levels in organizations. This research examines roles of organization policy in knowledge sharing. The results show that most organization does not have a knowledge sharing policy, which implies that most employees are working encyclopedia within the organization, and when such employee exist such organization they go along with their critical knowledge which might also possess security risk to the organization in the future. Different factors impede Knowledge sharing during the post-ERP phase. The study invoked rational action theory as well as their derivatives as theoretical foundations. From an interpretivist philosophy, the qualitative approach was used to gather data using interviews. The population of the study was sampled using a purposive and snowball method in order to obtain a representative sample of employees that work directly with both the development and use of the ERP system. The findings of the study showed that knowledge-sharing efforts were hampered by lack of organization policy, reciprocity
\end{abstract}

Keywords: Organization Policy, Impediments, Knowledge Sharing, ERP, Post Implementation

CISDI Journal Reference Format

Adegbenro, D.R., Longe, O.B. \& Okolo, O. (2019): Examining the Role of Organization Policy as Impediments to Knowledge Sharing in ERP

Post Implementation. Computing, Information Systems, Development Informatics \& Allied Research Journal. Vol 10 No 4, Pp 23-40. Available online at www.cisdijournal.org. DOI Affix - https://doi.org/ 10.22624/AIMS/CISDI/V10N4P7

\section{INTRODUCTION}

Knowledge management occupies a central place in today's knowledge-based economy. This is premised on the fact that productivity, performance, effectiveness, and competitive advantage are closely tied to the knowledge available to the organization (van Fenema, Soeters, \& Maas, 2016). The overarching nature of knowledge as the live-wire of an organization has aroused tremendous research interest in knowledge management across different organizations and professions (Paulin \& Suneson, 2015). It should be noted that knowledge management isn't an end to itself but a means to an end, therefore, there has been huge trend in knowledge management research whose focus has been shifted more towards knowledge sharing (Akgün, Keskin, Ayar, \& Okunakol, 2017a). 
The role of organization technology policy will be critically examine in this research due to prevailing problem with issue associated with ERP post implementation failure. Most organization today don't have technology knowledge sharing policy, which means knowledgeable employees are working encyclopedia, and when such knowledgeable employee leave the organization the whole system crumbles in most cases, because both tacit and explicit knowledge of such employee are not shared with team members. In other words, the rise of knowledge management systems research has been reinforced by the desire of an organization to share knowledge (Yossif \& Fouad, 2014). Knowledge sharing plays a significant role in repositioning knowledge management practices in supporting knowledge sharing within an organization (J. Chen, Jiao, \& Zhao, 2016a). The emergence of enterprise resource information systems has revolutionized organizational processes by enhancing the quality of deliverables in terms of integrating business processes, standardization of products, and simplification of daily business transactions that were otherwise in silos systems (Maditinos, Chatzoudes, \& Tsairidis, 2011).

The process of adoption, implementation, and post-implementation of enterprise resource information systems can be very daunting and sometimes with relative levels of successes, Lee, Lee, \& Park (2015). Knowledge sharing in the post-implementation of an enterprise resource system plays a vital role in ensuring that information, knowledge, ideas, skills, and expertise are shared among team members in order to enhance performance after implementation of an information system (Choshin \& Ghaffari, 2017a). However, there are many challenges hindering effective knowledge sharing within the organization. These hindrances have led to the relatively low success rate in the adoption and implementation of an ERP. Maditinos et al. (2011) revealed the result of the survey conducted by Marwick and Lausanne which reported that 35 percent of ERP project has budget overrun of the initial cost budgeted and about 25 percent of projects cannot be completed to deliver on its expected benefits. Grant and Dumay (2015) stressed that the factors interrupting the flow and dissemination of knowledge in an organization are an affront to innovation and productivity.

\subsection{Factors Influencing Knowledge sharing}

Different constructs interfere with the management of the dynamic aspects of organizational knowledge creation and sharing processes. Nonaka (1994) stressed that for knowledge sharing to happen in an organization there are four constructs that should be available, these are socialization, externalization, internalization, and combination. Yang and Maxwell (2011) argued that the predominant factor that influences knowledge sharing in an organization In the literature is whether it is expected at the interpersonal, intra-organizational, and inter-organizational levels. Pemsel \& Wiewiora (2013) claimed that the process of knowledge sharing between project teams in most organizations is inefficient. Furthermore, there is no dedicated entity responsible for capturing critical technical knowledge and disseminating it to other project teams to avoid investing resources in technical solutions that already exist. Similarly, Benaroch and Chernobai (2017) corroborated the above position and maintained that the absence of such an entity for a proper codification of the knowledge sharing process inhibits knowledge sharing between teams in an organization.

Benaroch and Chernobai (2017) further suggested that it is the responsibility of the IT governance members to impact knowledge sharing among software developers, and eventually avoid project failures arising from lack of information sharing. Research by Saifi, Dillon, and McQueen (2016) opined that management support is a major factor affecting knowledge sharing culture in an organization. The findings of their study indicated that top and middle managers could play a pivotal role in supporting knowledge sharing. The roles that could encourage knowledge-sharing culture includes; provision of recognition for employees who share crucial knowledge, breaking down organizational and personal barriers, building up of teams, encouraging or assigning some employee to carry out training of others, encouragement of formal and informal communication, putting knowledge into practice, and encouraging movement of employees. Razmerita, Kirchner, \& Nielsen (2016) added that three factors influence knowledge sharing in an organization. These are individual's factors, organizational factors, and technological factors. 


\subsection{Impact of knowledge sharing on information system}

The knowledge available to information technology staff is pivotal to their ability to deliver in the design and implementation of an information system. Schulz (2001) argues that knowledge is a broad concept that usually includes insights, interpretations, and information. Knowledge is more effectual and has far more reaching effect than information by its integrations of interpretations, where it is seen as something that can be transformed and acquired. Carlile (2004) stressed that knowledge is not only tacit, in the narrow sense of it being that which is not explicit, but also that knowledge and knowing cannot be separated from an individual's engagement in the practicing of their profession. There are many empirical works of literature that examine the influence of knowledge sharing on information system design and implementation in a firm. Some researchers investigated knowledge sharing as a learning and retention process. Others studied knowledge sharing as a process for enhancing team performance. These viewpoints are reviewed below.

Jeng and Dunk (2013) conducted a quantitative, non-experimental study to determine if there was a relationship between knowledge sharing and the success of enterprise resource planning (ERP) implementations. Their study used an online survey and recruited participants from North and South America. Their survey yielded 187 useable responses. The research found out that $13 \%$ of the surveyed organization responded in an affirmative that knowledge sharing significantly supports the installation of ERP systems. Their research later concluded that knowledge sharing among software developers assisted in the success of ERP installations.

In another study on how impactful knowledge sharing to information systems, Huang \& Zhang (2016) investigated the correlation between individual activities and knowledge sharing among IT professionals within an online medium. A particular online community platform known as "systems, applications, and products (SAP)" community network was used. The study discovered that both intrinsic and extrinsic motives directly of users on the platform impacted knowledge sharing and learning among information technology professionals.

(Carlsen, 2016) Used narrative analysis to study the role of employees in organizational knowledge sharing. The research focused on tacit organizational identity and its impact on employees. The study argued that organizations have tacit identities, and a tacit organizational identity is based on employee narrations and external influence and that identifying an organizational identity is a difficult task, but corporations differentiate themselves for strategic competitive advantage.

\subsection{Impediment to Knowledge sharing}

Knowledge sharing is considered a cherish organizational tradition in order to enhance performance in the workplace. However, there are many behavioral traits and structure that inhibits knowledge sharing. Razmerita, Kirchner, and Nielsen (2016a) opined that there is a concept referred to as a social dilemma, a situation in which individual rationality leads to collective irrationality. In other words, individuals attempt to maximize their self-interests and pay-offs, which make them inclined not to contribute to knowledge sharing and can consequently lead to collective damage. From a knowledge sharing perspective, a social dilemma can be seen as a situation where employees' individual interests conflict with organizational interest. Organizations have an interest in making knowledge available to all employees as public goods in order to improve their work performance, but from an employee's point of view it is a rational choice to hoard knowledge in order to feed their insecurity, conserve power and thereby remain valuable for the organization and reduce the risk of getting fired (Cress \& Kimmerle, 2008). An organization needs to set an orderly and an unambiguous statement for knowledge sharing to succeed. Knowledge sharing study by Mukkamala and Razmerita (2014) have emphasized that a lack of strategy and unclear business objectives or lack of perceived benefits for the users act as barriers to knowledge sharing. From the above, it could be inferred that personal gain and lack of organizational reward systems inhibit knowledge sharing within an organization. 


\section{THEORETICAL FOUNDATION}

Theoretical frameworks for this study were extracted from knowledge sharing literature in order to have a holistic view of the factors that impede knowledge sharing in the post-ERP implementation within an organization. Some of the theories proposed to investigate knowledge sharing in an organization which is relevant to this study are Social capital theory proposed by (H. W. Chou, Lin, Lu, Chang, \& Chou, 2014) and rational action theory proposed by (Hau, Kim, Lee, \& Kim, 2013). According to (Choshin \& Ghaffari, 2017b), social capital has three dimensions, namely structural dimension, cognitive, and structural dimension. (Hau et al., 2013) Research espoused the three dimension of the social capital theory mentioned by (Choshin \& Ghaffari, 2017b), added the individual motivation dimension.

\subsection{Conceptual Framework}

This paper used the theories such as social theory and relational theory as well as their construct as explained in our theoretical foundation to construct the conceptual framework for this study.

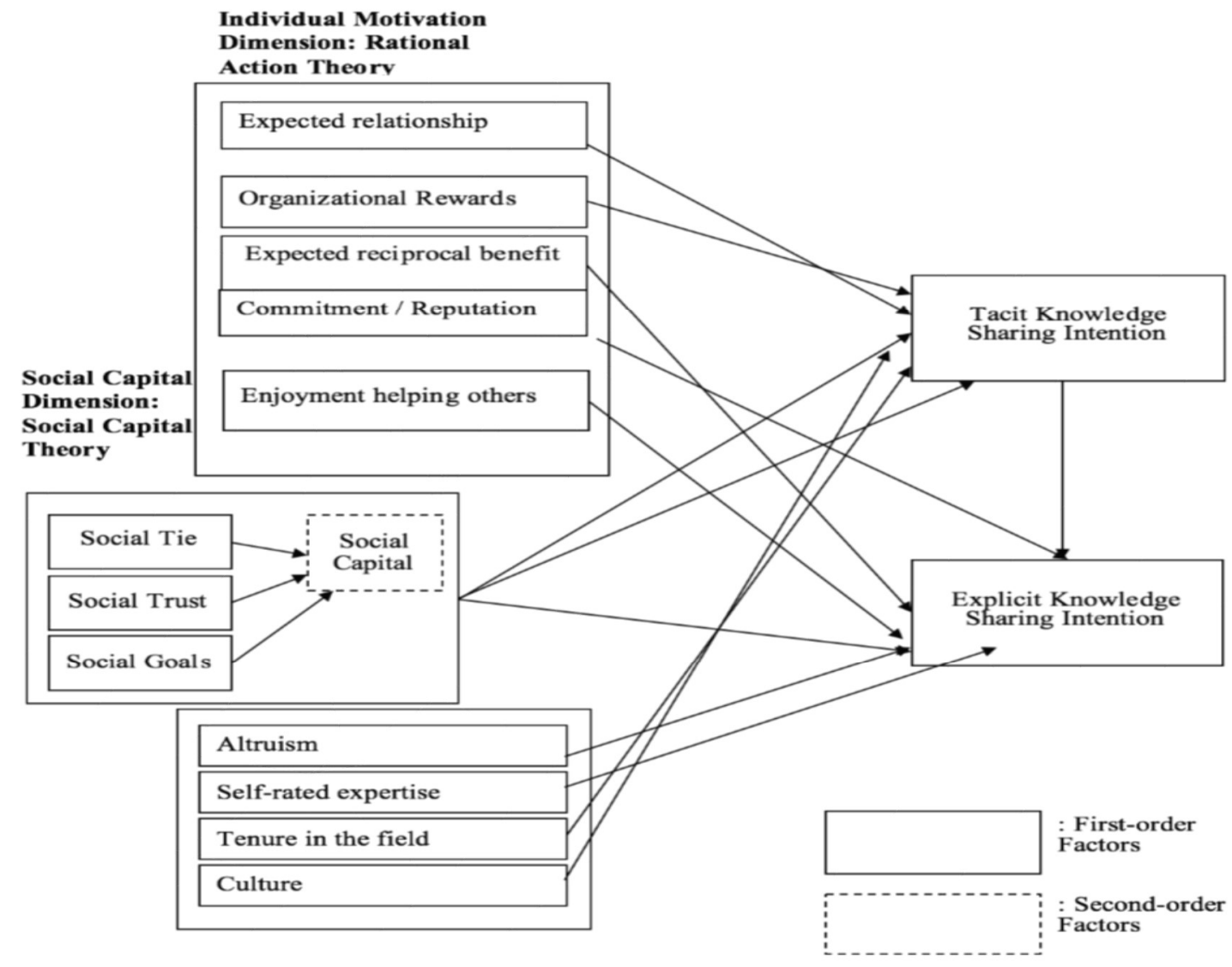

Figure 1: Knowledge sharing Model in organization 


\section{RESEARCH APPROACH}

This research follows an inductive approach because a qualitative research strategy been employed, the justification for adopting inductive approach is due to the paucity of literature on knowledge sharing, especially the post-ERP implementation. This study also adopts a case study method is the main concern for adopting case study research is the quality of its theoretical reasoning (Bryman \& Bell, 2011). This research also involves examination of a complex interaction and variables between individual, team or unit in an organization (from diverse background) who has various diverse concept of knowledge sharing and organization culture, this research is investigating a real situation on why ERP is not be used at maximum despite huge fund been spent on the project. In order to have a clear picture of the situation in-depth, the inductive approach will be adopted in order for the researcher to meet the set objective and aim of the study

\subsection{Method of Data Collection}

The most commonly use data collection method in qualitative research is focus group interview (group or individual), observation method and action research. A combination of two or more data collection methods (focus group, interview) enhances the research credibility, irrespective of the method of data collected adopted (Gill, Stewart, Treasure, \& Chadwick, 2008). This research adopted a structured interview as a means of data collection.Snowball Sampling, also known as chain referral sampling, is a method used in this study to select the participant for this research. The snowball sampling method involves primary data respondents to nominate another potential primary data source to be interviewed or recruited for the research (Emerson, 2018). The snowball method is based on referrals from the initial respondent interviewed. Data was collected from the different units concerned with OpenERP implementation. The participant demography is shown below

Table 1 - Participant Demography

\begin{tabular}{|l|l|l|l|l|l|}
\hline Group & Number & Age - Range & Gender & $\begin{array}{l}\text { No of years } \\
\text { working on ERP } \\
\text { systems }\end{array}$ & $\begin{array}{l}\text { Least } \\
\text { qualification }\end{array}$ \\
\hline Director & 9 & 40 - above & Male & $6-10$ & M.sc/ Phd \\
\hline Ass. Director & 12 & 40 - above & Male & 8 & M.sc/ B.sc \\
\hline Manager & 11 & 30 - above & Male /Female & 5 & M.sc/ B.sc \\
\hline Unit Team lead & 9 & 30 - above & Male / Female & $3-4$ & B.sc \\
\hline Team member & 9 & 25 - above & Male / Female & 3 & B.sc \\
\hline
\end{tabular}

A total of 50 participants were engaged via face to face interviews, while 12 participants were engaged via a focus group. Demography of participant interviewed in the table above includes senior management, middle management with the following portfolio Database Administrator, Data Architect, Business Analyst, software developer, Software support engineer, Network Manager, Director of Information systems, Ass. Director Network, academic advisor, senior Accountant, Payroll Manager, Reconciliation officer, Budget Manager, Budget analyst, Registrar, Ass. Registrar, Account officer. of Nigeria.

The researcher interviewed 50 participants, as against 20 participants recommend by (Creswell, 2007). There is no unique suggestion on what sample size is needed for thematic analysis (Guest, Bunce, \& Johnson, 2006). The sample size depends on the size of the project, type of data collection, and how the themes are analyzed and reported (Fugard \& Potts, 2015). 


\subsection{Data Analysis Method}

Data collected from the respondent in this research was analyzed using coding. The data was first audiotaped and later transcribed into a word document, and the observations were aggregated, a thematic analysis was performed on the transcribe data in order to enable viewpoints comparison across groups, this process involves the open-coding of text, followed by codes grouping into categories, the categories are then further sub-divided into various key themes (J. W. Creswell \& Miller, 2000b). The Microsoft word and Excel application was used to code and thematically analyze qualitative data because of its simple, cost-effective approach.

All data used in the research is collected from the different unit of the organization. The data analysis follows the following steps:

Stage 1 - Familiarity with data

Stage 2 - Initial codes generation

Stage 3 - Themes construction

Stage 4 - Review the identified themes

Stage 5 - Defining themes

Stage 6- Producing the write-up

\section{RESULT OF DATA ANALYSIS}

What follows is the presentation of results and data analysis

Stage one: The researcher coded the interview transcript using the table shown below

Table 2 : Interview Transcript Coded Theme

\begin{tabular}{|c|c|c|}
\hline Raw data & Preliminary codes & Final code \\
\hline $\begin{array}{l}\text { There is no policy in place that } \\
\text { guide or enforce employee to } \\
\text { share knowledge within } \\
\text { themselves, individual share their } \\
\text { knowledge at will, and in some } \\
\text { situations, they decide not to share } \\
\text { their knowledge, they cannot be } \\
\text { sanctioned since there is no policy } \\
\text { that gives the manager such power }\end{array}$ & $\begin{array}{ll}\text { i. } & \text { No policy } \\
\text { ii. } & \text { No enforcement to } \\
& \text { share knowledge } \\
\text { iii. } & \text { Knowledge is shared } \\
& \text { at will } \\
& \text { No sanction for not } \\
& \text { sharing knowledge }\end{array}$ & $\begin{array}{l}\text { i. Lack of policy } \\
\text { ii. Knowledge sharing at staff } \\
\text { volition }\end{array}$ \\
\hline $\begin{array}{l}- \\
-\end{array}$ & $\begin{array}{l}- \\
- \\
N\end{array}$ & $\begin{array}{c}- \\
\bar{N}\end{array}$ \\
\hline
\end{tabular}


All the raw interview data/transcript was conscientiously coded using this method with a view of obtaining the codes.

Stage two: The codes generated were pooled together as themes as shown in the table below

Table 3: Interview Transcript Coded Theme

\begin{tabular}{|c|c|c|}
\hline $\begin{array}{l}\text { Lack of access to previous knowledge } \\
\text { shared }\end{array}$ & Lack of infrastructure & Technological issue \\
\hline Lack of strict laws & Lack of law concerning knowledge sharing & Policy issue \\
\hline Lack of policy & $\begin{array}{l}\text { No clear policy that enforces employee to } \\
\text { share knowledge }\end{array}$ & Policy issue \\
\hline $\begin{array}{l}\text { No intention for future use from the } \\
\text { knowledge shared }\end{array}$ & $\begin{array}{l}\text { Unit manager intervention by providing an } \\
\text { alternate way to store knowledge }\end{array}$ & $\begin{array}{l}\text { Economic } \\
\text { Technical issue }\end{array}$ \\
\hline Incompetency of team members & need for sanction for incompetency & Mentorship issue \\
\hline Lack of training & Need for training for staff & Financial Issue \\
\hline Lack of mentoring & $\begin{array}{l}\text { Senior member unwillingness to mentor new } \\
\text { member of the team }\end{array}$ & Mentorship program \\
\hline Lack of policy & $\begin{array}{l}\text { Lack of strict policy and sanctions need to be } \\
\text { introduced }\end{array}$ & Awareness \\
\hline Power play among team members & $\begin{array}{l}\text { Negative personal agenda among team } \\
\text { members }\end{array}$ & Egoism \\
\hline Absorptive capacity & $\begin{array}{l}\text { Lack of intellectual capacity of knowledge } \\
\text { receiver }\end{array}$ & Training Issue \\
\hline Learning culture. & Bad learning culture & $\begin{array}{l}\text { Bad attitude to } \\
\text { learning }\end{array}$ \\
\hline
\end{tabular}

Stage three: The codes generated were pooled together and summarized to realign with the research theoretical constructs as shown in the table below

Table 4: Summary of themes generated from interview Codes

\begin{tabular}{|l|l|l|}
\hline Common themes & $\begin{array}{l}\text { Themes aligned with the } \\
\text { research model }\end{array}$ & Unexpected themes \\
\hline Lack of mentoring & Tenure in the field & Power play \\
\hline Lack of training & Social goals & Lack of policy \\
\hline Power play among team members & Organization reward & Lack of salary harmonization \\
\hline Reputation & Expected relationship & Frustration \\
\hline Learning culture. & Altruism & \\
\hline Lack of zeal or unwillingness to share & Social Trust & \\
\hline Lack of zeal to learn & Social Tie & \\
\hline No intention for future use & Culture & \\
\hline Unwillingness to share explicit knowledge & Motivation to share & \\
\hline Unwillingness to share explicit knowledge & reciprocity & \\
\hline Lack of knowledge repository & Commitment & \\
\hline Learning culture. & Enjoyment in helping other & \\
\hline Policy Issue & & \\
\hline
\end{tabular}




\section{DISCUSSION BASED ON THEORETICAL PERSPECTIVES}

\subsection{Organization perspective}

Rubenstein-Montano et al. (2001) opined that top management should ensure that organization goal and strategies aligned with knowledge sharing, from this research it was deduce that there is no macrocosmic that drives each team members on what type of knowledge either explicit or implicit needed to be stored and share for future use, and how to achieve the storage of such knowledge in a repository. From the interview, one of the critical reasons top management did not prioritize or pay attention to knowledge sharing is because the value of knowledge is hard to assess within the organization.

Furthermore, since there is no knowledge sharing policy and rules that guide knowledge sharing with organization sample in this research, which implies that employees have the autonomy concerning knowledge sharing, they share knowledge most times based on their discretion and conviction, most employees prefer to passively share knowledge with team members rather than archiving the knowledge assets for future use, they have negative attitude in storing their knowledge for future use, due to a lot of factors stated in table 9 . As a result of such attitude efficiency of work done is quite low, and team members use extra time and resources to seek for duplication of existing knowledge instead of seeking a piece of new knowledge.

\subsection{Organization supporting policy}

This is defined as the need to have a knowledge sharing policy or a framework in place to guide employees on how to go about knowledge sharing within the organization. The researcher deduce that policy alone can't solve the problem, knowledge sharing policy should be enforced and a sanction should be put in place for employee that does not follow the lay down policy concerning knowledge sharing. Team members within Information Technology, registrar, finance and advising department also believe that putting necessary policy, appropriate framework and awareness in place will curb resistance among team members that refuse to share either their tacit or implicit knowledge, having a documented knowledge sharing policy will give managers power and appropriate backing to enforce individual among its team to share knowledge among themselves whereby increasing team bonding and efficiency. Generally, the participants believe that putting an adequate policy in place will improve knowledge sharing in the organization.

\subsection{Individual Dimension}

Most employees claimed that it is necessary for the management to manage knowledge within the organization in order to increase the working productivity of the employees and high turnaround time for deliverables. However, some employees claimed they share their knowledge when their colleague request for help on a task, even if lack of trust exists among them or not, but the knowledge mostly share are explicit knowledge in nature, most respondent also state that they don't bother to share their knowledge when a colleague does not ask for help, to them is a way of recklessly showing off their skills.

Furthermore, some employees might hoard valuable knowledge that will be beneficial to other colleagues within a team, and it was also found out some individuals refuse to ask for help despite the fact they needed to help to be productive due to egoism. "There also exists a situation whereby recipients hoard useful knowledge and individual that seeks the knowledge cannot realize the right person who can help them accomplished the task effectively. Therefore, there should be a knowledge sharing strategy and awareness at the organization level that guides employees on knowledge sharing" (Nodari et al., 2016). 


\subsection{Reciprocity}

Reciprocity is one the important enabler of knowledge sharing; reciprocity actions is a rewarding activity in the future from the receiver of knowledge been shared, in a situation when the expected reaction is not coming forth, this greatly discourage the knowledge bearer. reciprocity to most individual is about cost and benefits, in the context of knowledge sharing within organization, the recipient of the knowledge decides if the knowledge recipient has the capacity to reciprocate positively in the future, most times in a highly competitive environment individual tends to ascertain the capacities of the knowledge recipient before exhibiting certain behavior that will either lead to them share either explicit or tacit knowledge, this most times lead to knowledge not been shared within an organization, because knowledge will not be shared between knowledgeable and non-knowledgeable employee. Reciprocity and trust are closely related when it comes to knowledge sharing, but they are quite different, trust enable an employee to maintain a reciprocal faith in each order in terms of behavior and intention, this enables team member to trust each other even when the receiver of knowledge can't reciprocate knowledge been received in the future.

\subsection{Demography of Result}

The qualitative research outcome shows that the respondent has a lot to say about the impact of Knowledge sharing on employee intention to share knowledge.

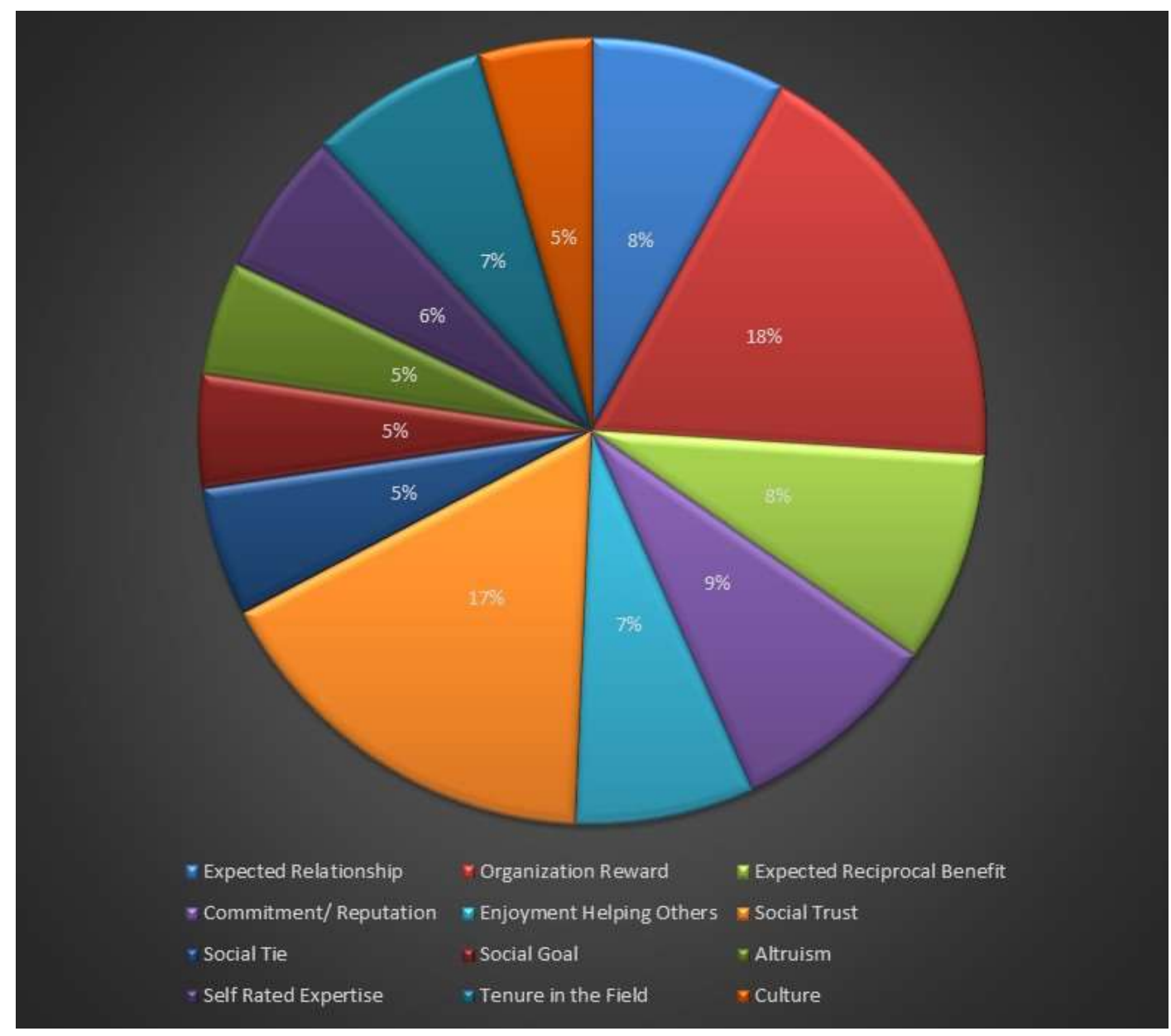

Fig 2: Pie Chart Showing Demographic Data 
The lack of structure, lack of policy, individualistic culture, lack of organization rewards, and trust were the main negative points that came out of the interviews. However, the interviewees did express they were not comfortable with the fact that Knowledge sharing events were not organized in most organizations. The respondents emphasized that they would like to see in the future more transparency and more obligatory events in order to educate employees on the role Knowledge sharing play in organization effectiveness and competitive advantage

\section{DISCUSSION AND CONCLUSION}

The empirical data shows that most organization has no policy in place that guides knowledge sharing among employees. This study also shows that the only knowledge sharing policy available is when staff is sent for training, he/she must come back and train team members concerning knowledge gained during the training, it is also deduced that knowledge share during such process is always explicit in nature and not documented for future use. To a certain extent, previous studies correlate the result, which reiterates the importance of an organization having knowledge sharing policy in place, and also understand individual employee expectation towards knowledge sharing, in order to promote knowledge sharing culture. Respondents who participate in the interview process reinstate that lack of policy positively influence knowledge sharing intentions. The conceptual framework is revised based on the result presented. The new redefined conceptual framework is an extension of the initial framework presented in Figure 1. The new revised conceptual framework answered research questions raised by the researcher.

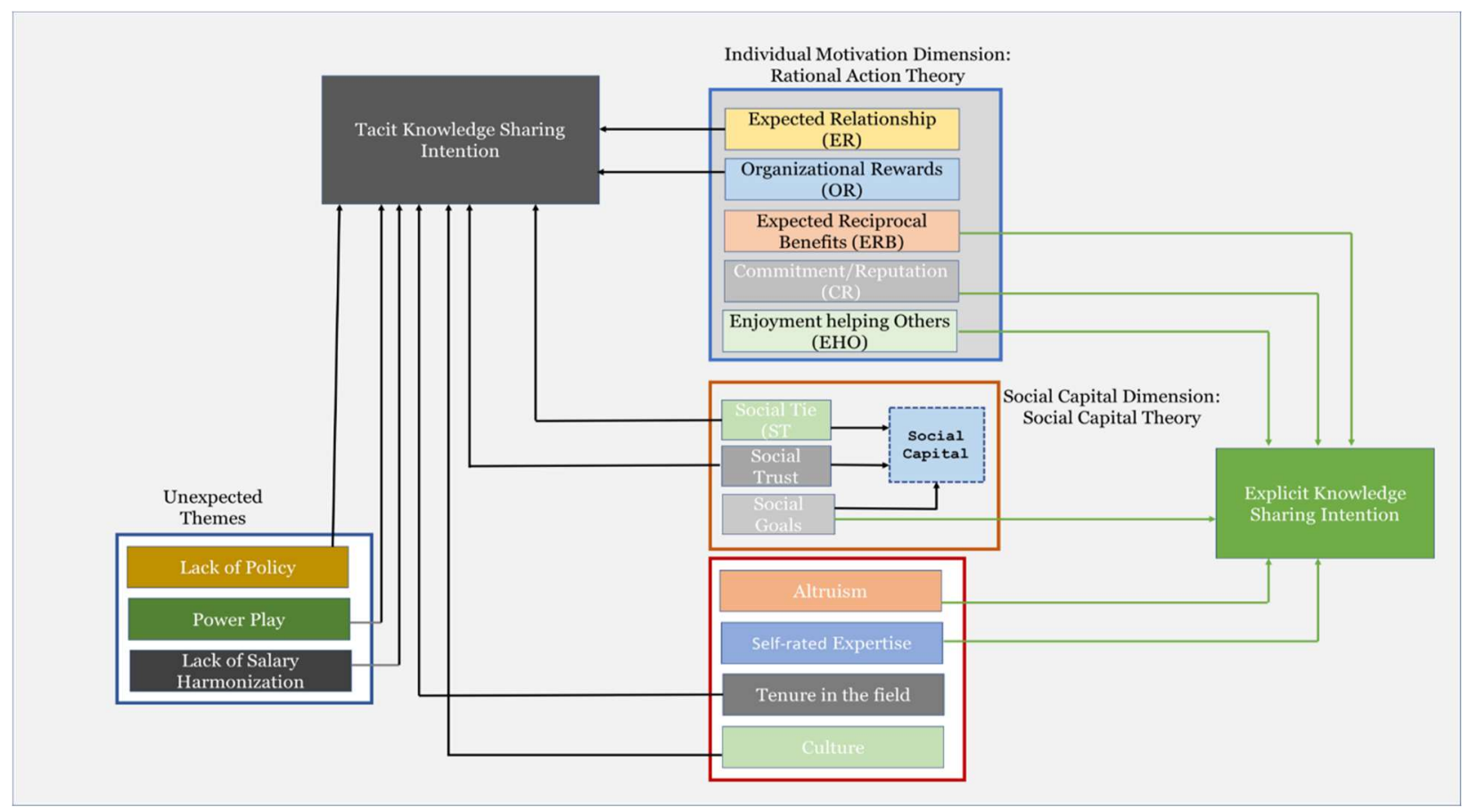

Fig. 3: Revised Framework for Knowledge Sharing Source: Field Work 


\subsection{Relational Capital Dimension}

The relational dimension in this study reiterates that knowledge sharing can be facilitated by an effective relationship within a collective group or individual within an organization, relational concepts considered in the study are a social tie, social trust, and social goals. This study shows that most employee has no trust among each other which is seriously hindering knowledge sharing intention among team members, this conforms with the study of (Telkamp, 2012) which reiterated that "Trust and shared social goals were found to have the greatest influence on a respondent's knowledge sharing behaviors.".

Furthermore, it was also deduced from the research that unit with less complain about ERP share knowledge among themselves based on social trust, social tie without having expectation from the receiver of the knowledge, such unit also has extensive internal departmental training program for new staff in order for the new staff to acclimatize with ERP, since their daily working routine is being done on the software. Among all the variables the researcher examines in the study, five factors found out to have a positive impact on knowledge sharing behavior were lack of trust, lack of knowledge sharing policy, reciprocity, share goals or vision, organization reward, altruism. Among all listed variables, trust has the greatest impact on employee knowledge sharing intention or behavior. It was also found out that trust positively influences virtually all the knowledge sharing variables tested in this research.

\subsection{Key findings of Relational Dimension}

Trust: Most of the participant point out lack of trust within the team as a major barrier that hinders knowledge sharing within their unit, they fear sharing their knowledge with colleague can be used against them in the future during promotion or performance evaluation, because after sharing your tacit knowledge and idea, team members present your idea as theirs in order for them to take the glory without acknowledging the owner of the knowledge been referenced.

Age: This study shows that age is also influential towards knowledge sharing intention, Age was seen to have an impact and influential factor in knowledge sharing intention within units. The study shows that younger employee is more likely not to share their knowledge, why the older employee doesn't have an issue sharing knowledge, because to them they have almost gotten to the peak of their career.

$>$ Education: This study also shows that education level also has a major role to play in employee intention to share its tacit knowledge it was deduced that employee with qualification with masters and Above don't feel threatened as such, they don't have an issue sharing knowledge with a less knowledgeable employee

\section{CONCLUSION}

The interpretive case study approach adopts in this study help to capture an in-depth view of the participant during the interview, the result from the study indicate that lack of knowledge sharing policy seriously hinders knowledge sharing intention within organization. The research suggests that top management should, in a matter of urgency, develop a policy that guides knowledge sharing and also put an appropriate sanction in place for defaulter of such policy due to the history of defaulting knowledge sharing training policy, in order to promote knowledge sharing organization-wide. Also, top management should prioritize employee motivation, either extrinsic or intrinsic, in order to encourage knowledge sharing. Future research should consider adopting a multiple case study to test these study findings, also a new theory like social exchange theory should be adopted. 


\section{LIMITATION AND FUTURE RESEARCH}

The limitation of this study is that the empirical findings cannot be generalized except in an organization that has the same organization settings and culture. future research should consider data analysis by region e.g., North East and southwest, also multiple case study should be seriously considered, this will increase the chance of generalizing the result. Future studies should also consider more sample size; this research is limited to 25 respondents, which might not capture the overall view of a situation in an organization. also during future data collection respondents should not be recorded during the interview, this will give them more freedom to state the fact with the assurance they cannot be quoted elsewhere

\section{REFERENCES}

1. Acar, M. F., Tarim, M., Zaim, H., Zaim, S., \& Delen, D. (2017). Knowledge management and ERP: Complementary or contradictory? International Journal of Information Management, 37(6), 703-712. https://doi.org/10.1016/j.jijnfomgt.2017.05.007

2. Açıkgöz, A., \& Günsel, A. (2016). Individual Creativity and Team Climate in Software Development Projects: The Mediating Role of Team Decision Processes. Creativity and Innovation Management, 25(4), 445-463. https://doi.org/10.1111/caim.12173

3. Aguinis, H., \& Solarino, A. M. (2019). Transparency and replicability in qualitative research: The case of interviews with elite informants. Strategic Management Journal, (April 2017), 1291-1315. https://doi.org/10.1002/smj.3015

4. Akgün, A. E., Keskin, H., Ayar, H., \& Okunakol, Z. (2017a). Knowledge sharing barriers in software development teams: a multiple case study in Turkey. Kybernetes. https://doi.org/10.1108/K-04-2016-0081

5. Akgün, A. E., Keskin, H., Ayar, H., \& Okunakol, Z. (2017b). Knowledge Sharing Barriers in Software Development Teams: A Multiple Case Study in Turkey. Kybernetes, 46(4), 603-620. https://doi.org/10.1108/K-04-2016-0081

6. Al-Alawi, A. I., Al-Marzooqi, N. Y., \& Mohammed, Y. F. (2007). Organizational culture and knowledge sharing: critical success factors. Journal of Knowledge Management. https://doi.org/10.1108/13673270710738898

7. Al-kurdi, O. (2018). Knowledge sharing in higher education institutions : a systematic review. https://doi.org/10.1108/JEIM-09-2017-0129

8. Alotaibi, H., Crowder, R., \& Wills, G. (2018). Adoption of Web Based Knowledge Sharing Systems amongst Academic Staff. Journal of Advanced Management Science, 5(1), 57-63. https://doi.org/10.18178/joams.5.1.57-63

9. Amayah, A. T. (2013). Determinants of knowledge sharing in a public sector organization. Journal of Knowledge Management. https://doi.org/10.1108/JKM-11-2012-0369

10. Ayodele, F. O., Haron, H. B., \& Juan, S. H. (2016). Review on Knowledge Sharing : Barriers and Motivations. The National Conference for Posgrduate Research, 225-237.

11. Bates, A. W. (2005). Technology, e-learning and Distance Education. https://doi.org/10.4324/9780203463772

12. Benaroch, M., \& Chernobai, A. (2017). Operational IT Failures, IT Value-Destruction, and Board-Level IT Governance Changes. MIS Quarterly, 69.

13. Brown, D. H., \& Thompson, S. (2011). Priorities, policies and practice of e-government in a developing country context: ICT infrastructure and diffusion in Jamaica. European Journal of Information Systems. https://doi.org/10.1057/ejis.2011.3 
14. Bryman, A. (2006). Integrating quantitative and qualitative research: How is it done? Qualitative Research, 6(1), 97-113. https://doi.org/10.1177/1468794106058877

15. Brzozowski, M. J. (2009). WaterCooler: Exploring an Organization Through Enterprise Social Media. Proceedings of the ACM 2009 International Conference on Supporting Group Work, 219-228. https://doi.org/10.1145/1531674.1531706

16. Caniëls, M. C. J., Neghina, C., \& Schaetsaert, N. (2017). Ambidexterity of employees: the role of empowerment and knowledge sharing. Journal of Knowledge Management, 21(5), 1098-1119. https://doi.org/10.1108/JKM-10-2016-0440

17. Caniëls, M., Neghina, C., \& Schaetsaert, N. (2017). Ambidexterity of employees: The role of empowerment and knowledge sharing. Journal of Knowledge Management, 00-00. https://doi.org/10.1108/JKM-10-20160440

18. Carlile, P. R. (2004). Transferring, Translating, and Transforming: An Integrative Framework for Managing Knowledge Across Boundaries. Organization Science, 15(5), 555-568. https://doi.org/10.1287/orsc.1040.0094

19. Carlsen, A. (2016). On the tacit side of organizational identity: Narrative unconscious and figured practice. Culture and Organization, 22(2), 107-135. https://doi.org/10.1080/14759551.2013.875016

20. Chang, C. L. hsing, \& Lin, T. C. (2015). The role of organizational culture in the knowledge management process. Journal of Knowledge Management, 19(3), 433-455. https://doi.org/10.1108/JKM-08-2014-0353

21. Chang, Y., Hsu, P., Shiau, W., \& Tsai, C. (2014). Knowledge sharing intention in the United States and China : a cross-cultural study. (July), 1-16. https://doi.org/10.1057/ejis.2014.28

22. Chang, Y. W., Hsu, P. Y., Shiau, W. L., \& Tsai, C. C. (2015). Knowledge sharing intention in the United States and China: A cross-cultural study. European Journal of Information Systems, 24(3), 262-277. https://doi.org/10.1057/ejis.2014.28

23. Chen, H., Baptista Nunes, M., Ragsdell, G., \& An, X. (2018). Extrinsic and intrinsic motivation for experience grounded tacit knowledge sharing in Chinese software organisations. Journal of Knowledge Management, 22(2), 478-498. https://doi.org/10.1108/JKM-03-2017-0101

24. Chen, J., Jiao, H., \& Zhao, X. (2016a). A knowledge-based theory of the firm: managing innovation in biotechnology. Chinese Management Studies. https://doi.org/10.1108/CMS-11-2015-0273

25. Chen, J., Jiao, H., \& Zhao, X. (2016b). A knowledge-based theory of the firm: managing innovation in biotechnology. Chinese Management Studies, 10(1), 41-58. https://doi.org/10.1108/CMS-11-2015-0273

26. Chen, J., Jiao, H., \& Zhao, X. (2016c). A knowledge-based theory of the firm: managing innovation in biotechnology. Chinese Management Studies. https://doi.org/10.1108/CMS-11-2015-0273

27. Cheng, H. H., \& Yang, H. L. (2014). The antecedents of collective creative efficacy for information system development teams. Journal of Engineering and Technology Management - JET-M. https://doi.org/10.1016/j.jengtecman.2013.12.001

28. Chofreh, A. G., Goni, F. A., \& Klemeš, J. J. (2018). Sustainable enterprise resource planning systems implementation: A framework development. Journal of Cleaner Production, 198, 1345-1354. https://doi.org/10.1016/j.jclepro.2018.07.096

29. Choshin, M., \& Ghaffari, A. (2017a). An investigation of the impact of effective factors on the success of ecommerce in small- and medium-sized companies. Computers in Human Behavior, 66, 67-74. https://doi.org/10.1016/j.chb.2016.09.026

30. Choshin, M., \& Ghaffari, A. (2017b). An investigation of the impact of effective factors on the success of ecommerce in small- and medium-sized companies. Computers in Human Behavior. https://doi.org/10.1016/j.chb.2016.09.026 
31. Choshin, M., \& Ghaffari, A. (2017c). An investigation of the impact of effective factors on the success of ecommerce in small- and medium-sized companies. Computers in Human Behavior. https://doi.org/10.1016/j.chb.2016.09.026

32. Chou, H. W., Lin, Y. H., Lu, H. S., Chang, H. H., \& Chou, S. Bin. (2014). Knowledge sharing and ERP system usage in post-implementation stage. Computers in Human Behavior. https://doi.org/10.1016/j.chb.2013.12.023

33. Chou, H.-W., Lin, Y.-H., Lu, H.-S., Chang, H.-H., \& Chou, S.-B. (2014). Knowledge sharing and ERP system usage in post-implementation stage. Computers in Human Behavior, 33, 16-22. https://doi.org/10.1016/j.chb.2013.12.023

34. Colnar, S., \& Dimovski, V. (2017). Knowledge management initiatives benefits for the Slovenian public sector. Journal of Contemporary Management Issues, 22(Special Issue), 145-161.

35. Connell, J., Kriz, A., \& Thorpe, M. (2014). Industry clusters: An antidote for knowledge sharing and collaborative innovation? Journal of Knowledge Management. https://doi.org/10.1108/JKM-08-2013-0312

36. Cress, U., \& Kimmerle, J. (2008). A systemic and cognitive view on collaborative knowledge building with wikis. International Journal of Computer-Supported Collaborative Learning, 3(2), 105. https://doi.org/10.1007/s11412-007-9035-z

37. Creswell, J., Shope, R., Clark, V. P., \& Green, D. O. (2006). How interpretive qualitative research extends mixed methods research. Research in the Schools, 13(1), 1-11.

38. Creswell, J. W., \& Miller, D. L. (2000a). D e t e r m in in g Vali d i t y in $Q$ u ali t a t ive I $n$ q u i $r y$. Theory into Practice, 39(3).

39. Creswell, J. W., \& Miller, D. L. (2000b). in Qualitative Inquiry. Theory and Practice, 39(3), 124-130.

40. Cui, X. (2017). In- and Extra-Role Knowledge Sharing Among Information Technology Professionals: The Five-Factor Model Perspective. International Journal of Information Management, 37(5), 380-389. https://doi.org/10.1016/j.jijinfomgt.2017.04.011

41. Cypress, B. S. (2017). Rigor or reliability and validity in qualitative research: Perspectives, strategies, reconceptualization, and recommendations. Dimensions of Critical Care Nursing, 36(4), 253-263. https://doi.org/10.1097/DCC.0000000000000253

42. Dang, C. N., Le-hoai, L., \& Kim, S. (2018). Impact of knowledge enabling factors on organizational effectiveness in construction companies. https://doi.org/10.1108/JKM-08-2016-0350

43. Dong, Y., Bartol, K. M., Zhang, Z.-X., \& Li, C. (2017). Enhancing Employee Creativity Via Individual Skill Development and Team Knowledge Sharing: Influences of Dual-Focused Transformational Leadership. Journal of Organizational Behavior, 38(3), 439-458. https://doi.org/10.1002/job.2134

44. Emerson, R. W. (2018). Convenience Sampling, Random Sampling, and Snowball Sampling: How Does Sampling Affect the Validity of Research? Journal of Visual Impairment \& Blindness, 109(2), 164-168. https://doi.org/10.1177/0145482x1510900215

45. Etikan, I., Alkassim, R., \& Abubakar, S. (2015). Comparision of Snowball Sampling and Sequential Sampling Technique. Biometrics \& Biostatistics International Journal, 3(1), 1-2. https://doi.org/10.15406/bbij.2016.03.00055

46. Fletcher, A. J., Macphee, M., \& Dickson, G. (2015). Doing Participatory Action Research in a Multicase Study: A Methodological Example. 1-9. https://doi.org/10.1177/1609406915621405

47. Forman, J., \& Damschroder, L. (2007). Qualitative Content Analysis. Advances in Bioethics, 11, 39-62. https://doi.org/10.1016/S1479-3709(07)11003-7

48. Fullwood, R., Rowley, J., \& McLean, J. (2018). Exploring the factors that influence knowledge sharing between academics. Journal of Further and Higher Education, 9486, 1-13.

https://doi.org/10.1080/0309877X.2018.1448928 
49. Ghafouri, R. (2018). Trustworth and Rigor in Qualitative Research Trustworth and Rigor in Qualitative Research ABSTRACT : (January 2016).

50. Ghobadi, S. (2015). What drives knowledge sharing in software development teams: A literature review and classification framework. Information \& Management, 52(1), 82-97. https://doi.org/10.1016/j.im.2014.10.008

51. Giampaoli, D., Ciambotti, M., \& Bontis, N. (2017). Knowledge management, problem solving and performance in top Italian firms. Journal of Knowledge Management. https://doi.org/10.1108/JKM-03-20160113

52. Gill, P., Stewart, K., Treasure, E., \& Chadwick, B. (2008). Methods of data collection in qualitative research: Interviews and focus groups. British Dental Journal, 204(6), 291-295. https://doi.org/10.1038/bdj.2008.192

53. Grant, K., \& Dumay, J. (2015). Leading Issues in Knowledge Management. Academic Conferences and publishing limited.

54. Gray, D. E. (2013). Doing Research in the Real World. SAGE.

55. Hamilton, J. B. (2019). Rigor in Qualitative Methods: An Evaluation of Strategies Among Underrepresented Rural Communities. Qualitative Health Research, 104973231986026. https://doi.org/10.1177/1049732319860267

56. Hau, Y. S., Kim, B., Lee, H., \& Kim, Y. G. (2013). The effects of individual motivations and social capital on employees' tacit and explicit knowledge sharing intentions. International Journal of Information Management, 33(2), 356-366. https://doi.org/10.1016/j.ijinfomgt.2012.10.009

57. Holdt Christensen, P., \& Pedersen, T. (2018). The dual influences of proximity on knowledge sharing. Journal of Knowledge Management, 22(8), 1782-1802. https://doi.org/10.1108/JKM-03-2018-0211

58. Hooff, B. van den, Schouten, A. P., \& Simonovski, S. (2012). What one feels and what one knows: the influence of emotions on attitudes and intentions towards knowledge sharing. Journal of Knowledge Management. https://doi.org/10.1108/13673271211198990

59. Houghton, C., \& Keynes, M. (2013). case-study research. 12-17.

60. Hsu, C. L., \& Lin, J. C. C. (2008). Acceptance of blog usage: The roles of technology acceptance, social influence and knowledge sharing motivation. Information and Management, 45(1), 65-74. https://doi.org/10.1016/j.im.2007.11.001

61. Huang, P., \& Zhang, Z. (2016). Participation in open knowledge communities and job-hopping: Evidence from enterprise software. MIS Quarterly, 40, 785-806.

62. Hung, S.-Y., Lai, H.-M., \& Chang, W.-W. (2011). Knowledge-sharing motivations affecting R\&D employees' acceptance of electronic knowledge repository. Behaviour \& Information Technology, 30(2), 213-230. https://doi.org/10.1080/0144929X.2010.545146

63. Jasimuddin, S. M., Klein, J. H., \& Connell, C. (2005). The paradox of using tacit and explicit knowledge. Management Decision. https://doi.org/10.1108/00251740510572515

64. Javadi, M., \& Zarea, K. (2016). Understanding Thematic Analysis and its Pitfall. (January). https://doi.org/10.15412/J.JCC.02010107

65. Jeng, D. ., \& Dunk, N. (2013). Knowledge Management Enablers and Knowledge Creation in Erp System Success. International Journal of Electronic Business Management, 11(1), 49-59.

66. Jin-Feng, W., Ming-Yan, C., Li-Jie, F., \& Jun-Ju, Y. (2017). The Construction of Enterprise Tacit Knowledge Sharing Stimulation System Oriented to Employee Individual. Procedia Engineering, 174, 289-300. https://doi.org/10.1016/j.proeng.2017.01.139

67. Journal, A., \& Volume, P. (2017). Understanding the Unknown : A Thematic Analysis of Subjective Paranormal Experiences. 17(1), 23-46.

68. Kassens-Noor, E. (2012). Twitter as a teaching practice to enhance active and informal learning in higher education: The case of sustainable tweets. Active Learning in Higher Education, 13(1), 9-21. https://doi.org/10.1177/1469787411429190 
69. Kaya, Y. (2013). Comparison of Quantitative and Qualitative Research Traditions : epistemological , theoretical. European Journal of Education, 48(2), 311-325. https://doi.org/doi:10.1111/ejed.12014

70. Keszey, T. (2018). Boundary spanners' knowledge sharing for innovation success in turbulent times. Journal of Knowledge Management, 22(5), 1061-1081. https://doi.org/10.1108/JKM-01-2017-0033

71. Kharabsheh, R., Bittel, N., Elnsour, W., Bettoni, M., \& Bernhard, W. (2016). A comprehensive model of knowledge sharing. Proceedings of the European Conference on Knowledge Management, ECKM, 2016Janua, 454-461.

72. Kuettner, T., Diehl, R., \& Schubert, P. (2013). Change factors in Enterprise 2.0 initiatives: Can we learn from ERP? Electronic Markets, 23(4), 329-340. https://doi.org/10.1007/s12525-013-0141-7 